\title{
Defined Criterion Group Composition Relationship
}

National Cancer Institute

\section{Source}

National Cancer Institute. Defined Criterion Group Composition Relationship. NCI

Thesaurus. Code C93458.

A relationship between a criterion group and an activity, observation result or other criterion group that is a component of the group, i.e. a relationship between a logical set of parenthesis and one of the items inside the parentheses, where the criterion group and its components are both part of a global library of activities. 